\section{What is already known on this topic}

Placebo devices are thought to have enhanced placebo effects compared with oral pills, but rigorous evidence is lacking

Controversy exists over the existence of placebo effects over and beyond the natural course of disease and whether information provided by informed consent influences reports of adverse events

\section{What this study adds}

A validated sham acupuncture device has a greater placebo effect on subjective outcomes than oral placebo pills

A placebo analgesia effect beyond the natural course of disease is detectable over time

Adverse events and nocebo effects are linked to the information provided to patients

We thank Peter Goldman, Fred Mosteller, and John HedleyWhyte for scientific mentorship; Melbeth Marlang, Lin Nulman, Patricia Muldoon, and Pat Wilkinson for research assistance; Joe Kay, Claire McManis, Bella Rosner, Ellen Highfield, Jonathan Ammen, Nancy Jenkins, Mark Mills, Karen Kirchoff, and Dinah Shatz for performing the acupuncture treatments; Sidney Klawansky, Dan Moerman, Robert Scholten, Frank Miller, Julie Buring, Marnie Naeser, and the University Seminar on Effective and Affordable Health Care at Harvard University for important feedback on study design and analysis; and
Jacqueline Savetsky, Andrea Hrbek, Robb Scholten, and Sally Andrews for administrative coordination.

Contributors: See bmj.com.

Funding: This study was made possible by grant No 1RO1 AT00402-01 from the National Center for Complementary and Alternative Medicine (NCCAM) at the NIH.

Competing interests: TJK works as a consultant for Kan Herbal Co, Scotts Valley, CA.

Ethical approval: The institutional review boards of Cambridge Health Alliance, Beth Israel Deaconess Medical Center, Harvard Medical School, and Harvard School of Public Health approved the study.

Kaptchuk TJ. Powerful placebo: the dark side of the randomised controlled trial. Lancet 1998; 351: 1722-5.

http://placebo.nih.gov (accessed on 28 July 2005)

Guess HA, Kleinman A, Kusek JW, Engel LW. The science of the placebo: toward an interdisciplinary research agenda. London: BMJ Publishing, 2002.

Hróbjartsson A, Gøtzsche PC. Is the placebo powerless? An analysis of clinical trials comparing placebo with no treatment. $N$ Engl J Med 2001;344:1594-602.

5 Kaptchuk TJ, Goldman P, Stone DA, Stason WB. Do medical devices have enhanced placebo effects? J Clin Epidemiol 2000;53:786-92.

6 Miller FG, Emanuel EJ, Rosenstein DL, Straus SE. Ethical issues concerning research in complementary and alternative medicine. JAMA 2004;291:599-604

7 Levine DW, Simmons BP, Koris MJ, Daltroy LH, Hohl GG, Fossel AH, et al. A self-administered questionnaire for the assessment of severity of symptoms and functional status in carpal tunnel syndrome.J Bone Join Surg Am 1993;75:1585-92.

8 Pransky G, Feuerstein M, Himmelstein J, Katz JN, Vickers-Lahti M. Measuring functional outcomes in work related upper extremity disorders. $J$ Occup Environ Med 1997:39:1195-202

9 Benedetti F, Mayberg HS, Wagner TD, Stohler CS, Zubieta JK. Neurobiological mechanisms of the placebo effect. J Neuroscience 2005;25:10390402

10 Kong J, Gollub RL, Rosman IS, Webb JM, Vangel MG, Kirsch I, et al. Brain activity associated with expectancy-enhanced placebo analgesia as measured by functional magnetic resonance imaging. $J$ Neuroscience 2006;26:281-8.

(Accepted 8 November 2005)

doi 10.1136/bmj.38726.603310.55

\title{
Importance of free access to research articles on decision to submit to the $B M J$ : survey of authors
}

Sara Schroter

\section{$B M J$, London} WC1H 9JR

Sara Schroter senior researcher sschroter@bmj.com

BMJ 2006;332:394-6

\author{
Abstract \\ Objectives To determine whether free access to \\ research articles on bmj.com is an important factor in \\ authors' decisions on whether to submit to the $B M J$, \\ whether the introduction of access controls to part of \\ the $B M /$ s content has influenced authors' perceptions \\ of the journal, and whether the introduction of \\ further access controls would influence authors' \\ perceptions. \\ Design Cross sectional electronic survey. \\ Participants Authors of research articles published in \\ the $B M J$. \\ Results 211/415 (51\%) eligible authors responded. \\ Three quarters (159/211) said the fact that all readers \\ would have free access to their paper on bmj.com was \\ very important or important to their decision to \\ submit to the $B M J$. Over half $(111 / 211)$ said closure of \\ free access to research articles would make them \\ slightly less likely to submit research articles to the \\ $B M J$ in the future, $14 \%(29 / 211)$ said they would be \\ much less likely to submit, and $34 \%(71 / 211)$ said it
}

would not influence their decision. Authors were equally divided in their opinion as to whether the closure of access to parts of the journal since January 2005 had affected their view of the BMj; $40 \%$ $(84 / 211)$ said it had, $38 \%(80 / 211)$ said it had not. In contrast, $67 \%(141 / 211)$ said their view of the $B M J$ would change if it closed access to research articles. Authors' comments largely focused on disappointment with such a regressive step in the era of open access publishing, loss of a distinctive feature of the $B M J$, a perceived reduction in the journal's usefulness as a resource and global influence, restricted readership, less attractive to publish in, and the negative impact on the journal's image. Conclusions Authors value free access to research articles and consider this an important factor in

A copy of the electronic survey and details of all responses as received are on bmj.com.

This article was posted on bmi.com on 9 January 2006: http://bmi.com/ cgi/doi/10.1136/bmj.38705.490961.55 


\section{Responses to survey questions $(n=211)$}

No $(\%)^{*}$

Importance of free access in your decision to submit your paper to the $B M J$

\begin{tabular}{lc}
\hline Very important & $79(37)$ \\
\hline Important & $80(38)$ \\
\hline Neither important nor unimportant & $42(20)$ \\
\hline Unimportant & $7(3)$ \\
\hline Very unimportant & $3(1)$ \\
\hline
\end{tabular}

If we closed access to research articles would this influence the likelihood of your submitting to the $B M J$ in future?

\begin{tabular}{lc}
\hline Much less likely to submit & $29(14)$ \\
\hline Slightly less likely to submit & $111(53)$ \\
\hline No influence on decision to submit & $71(34)$
\end{tabular}

Has closure of access to parts of the journal on bmj.com affected your view of the BMJ?

\begin{tabular}{ll}
\hline Yes & $84(40)$ \\
\hline No & $80(38)$ \\
\hline Not aware you had closed access to parts of the journal & $47(22)$
\end{tabular}

If we closed access to research articles would this change your view of the BMJ?

\begin{tabular}{lc}
\hline Yes & $141(67)$ \\
\hline No & $42(20)$ \\
\hline Don't know & $28(13)$ \\
\hline
\end{tabular}

${ }^{*}$ Numbers do not total $100 \%$ because of rounding.

deciding whether to submit to the BMJ. Closing access to research articles would have a negative effect on authors' perceptions of the journal and their likeliness to submit.

\section{Introduction}

The traditional publishing model based on subscriptions from readers has been heavily criticised for restricting access to important scientific information while generating large profits for publishers. ${ }^{12}$ Realising the importance of free unrestricted access to scientific information, the $B M J$ introduced an open access policy in 1998, whereby all readers could gain free access to all journal content online with no restrictions. ${ }^{3}$ Free access to content, however, comes with a financial cost to the BMJ Publishing Group through a potential loss of subscriptions. Reduced revenue from subscriptions was one of the key reasons for putting some content (including editorials and education and debate articles) behind access controls in January 2005. ${ }^{4}$ The BMJ, however, has retained free access to all original research articles on bmj.com. While free access to research articles is important to BMJ editors we do not know how much our authors value it and how they would perceive the introduction of access controls for this material.

\section{Methods}

I emailed the first author of 479 research articles (papers, primary care papers, and short reports) published in the $B M J$ between 1 January 2003 and 31 March 2005 an invitation from the BMJ to complete an electronic survey (see bmj.com). I excluded authors of papers who were not categorised initially on our manuscript tracking system.

\section{Results}

Sixty four email addresses were incorrect, and 51\% $(211 / 415)$ of the remaining authors responded. Most
$(75 \%, 159 / 211)$ said the fact that all readers would have free access to the specific paper they had published on bmj.com was very important or important to their decision to submit their paper to the $B M J$ (table).

I asked authors whether closure of free access to research articles would influence the likelihood of their submitting research articles to the $B M J$ in the future. Most $(53 \%, 111 / 211)$ said they would be slightly less

\section{Sample quotes showing how authors' views have been affected}

How the closure of access to parts of the journal content has affected authors' views

Regressive step in the era of open access

I saw the free access part of the $B M J$ as a key part of its identity and role as a disseminator of information and evidence. It also contributes to its image of acting in the public good and for the betterment of public health. I was very disappointed with the decision to limit access at a time when so many other organisations are moving towards freer access. It seemed a profit driven move for an organisation that I had assumed had a more balanced view of the world

$B M J$ is swimming against the tide. Other journals are moving towards open access and you are going in the opposite direction. This is a real pity

When I realised that $B M J$ allowed the free access, I was very much impressed with $B M / \mathrm{s}$ progressive view and courage in the forefront leading to free distribution of knowledge. On the other hand, if this policy is not viable for business reasons, I can totally understand.

Reduced usefulness as a resource

I think that it was really good that the journal was freely available. I know lots of people who used to use it as a resource but can't do this anymore. It is really important that papers and the views of experts-for example, in your education and debate articles and editorials-should be made widely available. Your editorials, for example, are very widely read.

Reduced global influence

Less access globally means less readership, less impact of papers, and less recognition and awareness of publications

Restricted readership

Public access, particularly to patient populations, was a strong attribute of $B M J$ and I am sad to see it go

Less attractive to publish in

It is no longer widely available. Less likely to be referenced over an article that was available in full text from another leading journal

Negative impact on journal's image

I wonder about the $B M j$ s s commitment to public education. Many staff and hospitals simply cannot afford the online subscription rates that journals charge

How putting research articles behind access controls would change authors' views of the $B M J$

Loss of a unique feature of the BMJ

I was proud of the $B M J$ for making universal free access and leading the world in this. Now it has gone back to being just another journal

I would view the $B M J$ as a more ordinary journal and not as the most important journal in medicine. In my opinion, the $B M J$ is one of the few uncorrupt journals in today's medicine, and not totally in the hands of commercial (for instance, pharmaceutical) companies. I therefore believe the journal has an extraordinary important position in medicine. The journal must be freely available to hold this position

Financial interest

I would assume that the $B M J$ was in financial meltdown and would not be with us for much longer

I would regard the $B M J$ as just one of those journals out to get money any way they can. 


\section{What is already known on this topic}

BMJ editors are committed to free open access to research articles but have no data on how important this is to authors

\section{What this study adds}

Authors value free access to research articles on bmj.com and this influences their choice of where to submit articles

The introduction of access controls to part of the $B M J$ s content has influenced authors' perceptions of the journal

likely to submit and $14 \%$ (29/211) would be much less likely to submit. A third (71/211) said this would not influence their decision.

Authors were equally divided in their opinion as to whether the closure of access to parts of the journal since January 2005 had affected their view of the $B M J$ : $40 \%(84 / 211)$ said it had and 38\% (80/211) said it had not. Around a fifth $(47 / 211)$ were not aware that we had closed access to parts of the journal, possibly because they have institutional subscriptions allowing automatic full access. In contrast, two thirds of authors $(141 / 211,67 \%)$ said their view of the $B M J$ would change if we closed access to research articles, $20 \%(42 / 211)$ said it would not change their view, and $13 \%(28 / 211)$ were not sure.

The box gives some illustrative sample quotes of how authors' views of the $B M J$ have been affected since we closed access to parts of the journal and how their views would be affected if we closed access to research papers. Comments largely focused on disappointment with a regressive step in the era of open access publishing, loss of a unique feature of the $B M J$ "that sets you apart from most other major journals," a perceived reduction in the journal's usefulness as a resource and global influence, restricted readership, less attractive to publish in, and the negative impact on the journal's image. None of the quotes were negative about open access. All the comments received from authors are available on bmj.com.

\section{Discussion}

Authors clearly value free access to $B M J$ research articles and consider this an important factor in deciding whether to submit to the journal. Closing access to research articles would have a negative effect on authors' perceptions of the journal and their likeliness to submit.

This study was limited by a low response rate (51\%) and unfortunately I cannot compare responders and non-responders in terms of demographics and research experience as this type of information about individual authors is not kept. One possible reason for the low response rate was that the $B M J$ was simultaneously conducting another online author survey and authors may have felt overburdened. The response rate, however, is comparable with rates of other surveys with professionals (published surveys of physicians have a mean response rate of 54\%). ${ }^{5}$ Responding authors may have tried to emphasise a particular message to the publishing group and may have been advocates of open access publishing in general. Regardless, the results show that the issue was important to many authors, even if all the non-responders were indifferent.
The individual comments from participants suggest that closure of access to research articles is likely to have a considerable negative impact on the image, and therefore potentially the strategic and long term financial success and viability, of the $B M J$. The publishing group has agreed to keep free access to research articles for now.

I thank all the authors who completed the survey.

Contributors: SS is the sole contributor.

Funding: BMJ Publishing Group.

Competing interests: SS is employed by the $B M J$ as a researcher. She believes free access to research articles is important but did not reveal this to the participants when communicating with them.

Ethical approval: Not required.

Because a member of $B M J$ editorial staff conducted this research, assessment and peer review were carried out entirely by external advisers. No member of $B M J$ staff was involved in making the decision on the paper.

1 Hopkins C. Healthy warning: this journal supports full text, tariff-free archives. Nature webdebates 2001. www.nature.com/nature/debates/eaccess/Articles/hopkins.html (accessed 7 July 2004).

2 Eisen M, Brown P. Should the scientific literature be privately owned and controlled? Nature webdebates 2001. www.nature.com/nature/debates/eaccess/Articles/Eisen.htm (accessed 7 July 2004.)

access/Articles/Eisen.htm (accessed 7 July 2004.)
Godlee F. Open access, and proud of it. BMJ 2005;330. (2 April.)

Delamothe T, Smith R. Paying for bmj.com. BMJ 2003;327:241-2

5 Asch DA, Jedrziewski AK, Christakis NA. Response rates to mail surveys published in medical journals. J Clin Epidemiol 1997;50:1129-36. (Accepted 8 October 2005)

doi 10.1136/bmj.38705.490961.55

\section{Corrections and clarifications}

Interactive case report: an alcoholic patient who continues to drink: case outcome

Technical failure and editorial oversight led to the omission of one of the commentaries from the final part of the interactive case report by Stuart McPherson and Colin John Rees (BMJ 2006;332:276, 4 Feb). The commentary, by Mark Hudson, is now available at http://

bmj.bmjjournals.com/cgi/content/full/332/7536/ 276/DC1) and in our letters pages this week (p 423).

Patients get four choices for NHS treatments We've again failed to acknowledge the effects of devolution on the organisation of health care in the United Kingdom. In this news article by Rebecca Coombes, we did not clarify that the new legislation requiring general practitioners to offer patients a choice of four providers for elective treatment applies only in England (BMJ 2006;332:8, 7 Jan). And Patricia Hewitt's role is English secretary of state for health; she is not the health secretary for the United Kingdom.

Barriers to using warfarin in non-valvular atrial fibrillation

Unfortunately, in the printed journal, the order of authors in this letter by Melina Gattellari and colleagues (BMJ 2006;332:303-4, 4 Feb) was changed from the order submitted by the authors. The letter was first posted on our website as a rapid response with the correct order (Melina Gattellari, John M Worthington, Nicholas A Zwar, Sandy Middleton). In the printed journal, we switched Worthington and Zwar in order to group authors by address, which saves space. This reflects our policy with letters, and we intend to make this policy clearer on our website. 